\title{
Micro gas turbine simulation and control
}

\author{
Ibrahim Ahmed El-Sharif ${ }^{1}$, Mahmoud Mansour El- Fandi ${ }^{2}$ \\ ${ }^{1}$ Instrument department, General electrical company of Libya, GECOL, Khoms, Libya \\ ${ }^{2}$ Electrical and electronic engineer, Faculty of engineering, Tripoli-university, Tripoli, Libya \\ DOI: https://doi.org/10.21467/proceedings.2.19 \\ * Corresponding author email: Ssssharif2004@yahoo.com
}

\begin{abstract}
Gas turbines are widely used in power generation plants due to their compactness, fast start-stop sequences, and their applications, and...etc. A split shaft micro-turbine mechanical model is used. Three main controllers for three different loops have been designed and discussed. MATLAB/Simulink environment is used to represent the mechanical model for Micro-turbine spilt shaft. A speed PID controller, exhaust temperature PI controller, and mechanical \& electrical power PID controller all have been designed with MATLAB/Simulink. Compensators have also been used instead of PI and PID controllers which had been used for three systems. A comparison between PI, PID controllers, and its corresponding compensator have been done through this research. At last a supervisory controller for three systems has been done. A MIMO system - Multi-Input Multi-Output -will be reduced to a SISO system - Single-Input Single-Output - during system design.
\end{abstract}

Keywords: MGT: Micro-Gas turbine, LVG: Least Value Gate, MIMO: Multi Input Multi Output

\section{Introduction}

Single-shaft MGT models are designed to operate at high speeds (some in excess of 100,000 revolutions per minute $[\mathrm{RPM}]$ ) and generate electric power as high-frequency alternating current (AC). The generator output is rectified to direct current (DC) and then inverted to 60 hertz $(\mathrm{Hz}) \mathrm{AC}$ for commercial use in the United States, or $50 \mathrm{~Hz}$ for use in countries with a $50 \mathrm{~Hz}$ supply. Two-shaft MGT micro-gas turbines have a turbine-driven compressor on one shaft and a separated "free" power turbine on a second shaft to power the generator. (In conventional gas turbines, this arrangement is generally used in mechanical drive service, as the free power turbine, generally via a gear box, then runs other turbo-machinery, such as compressors or pumps.) With the expansion pressure ratio split between two turbines, the power turbine on a two-shaft machine can be designed to run at lower speed with high efficiency. Split-shaft design uses a power turbine rotating at $3000 \mathrm{rpm}$ and a conventional generator connected via a gearbox for speed multiplication [1]. The figure (1) illustrate a splitshaft micro-turbine as was have been chosen in this paper which consists of two main turbines

(C) 2018 Copyright held by the author(s). Published by AIJR Publisher in Proceedings of First Conference for Engineering

Sciences and Technology (CEST-2018), September 25-27, 2018, vol. 1 .
This is an open access article under Creative Commons Attribution-NonCommercial 4.0 International (CC BY-NC 4.0) license, which permits any non-commercial use, distribution, adaptation, and reproduction in any medium, as long as the original work is properly cited. ISBN: 978-81-936820-5-0 
Micro gas turbine simulation and control

one for compressor driving and the other for driving conventional generator which connected with a gearbox [2]

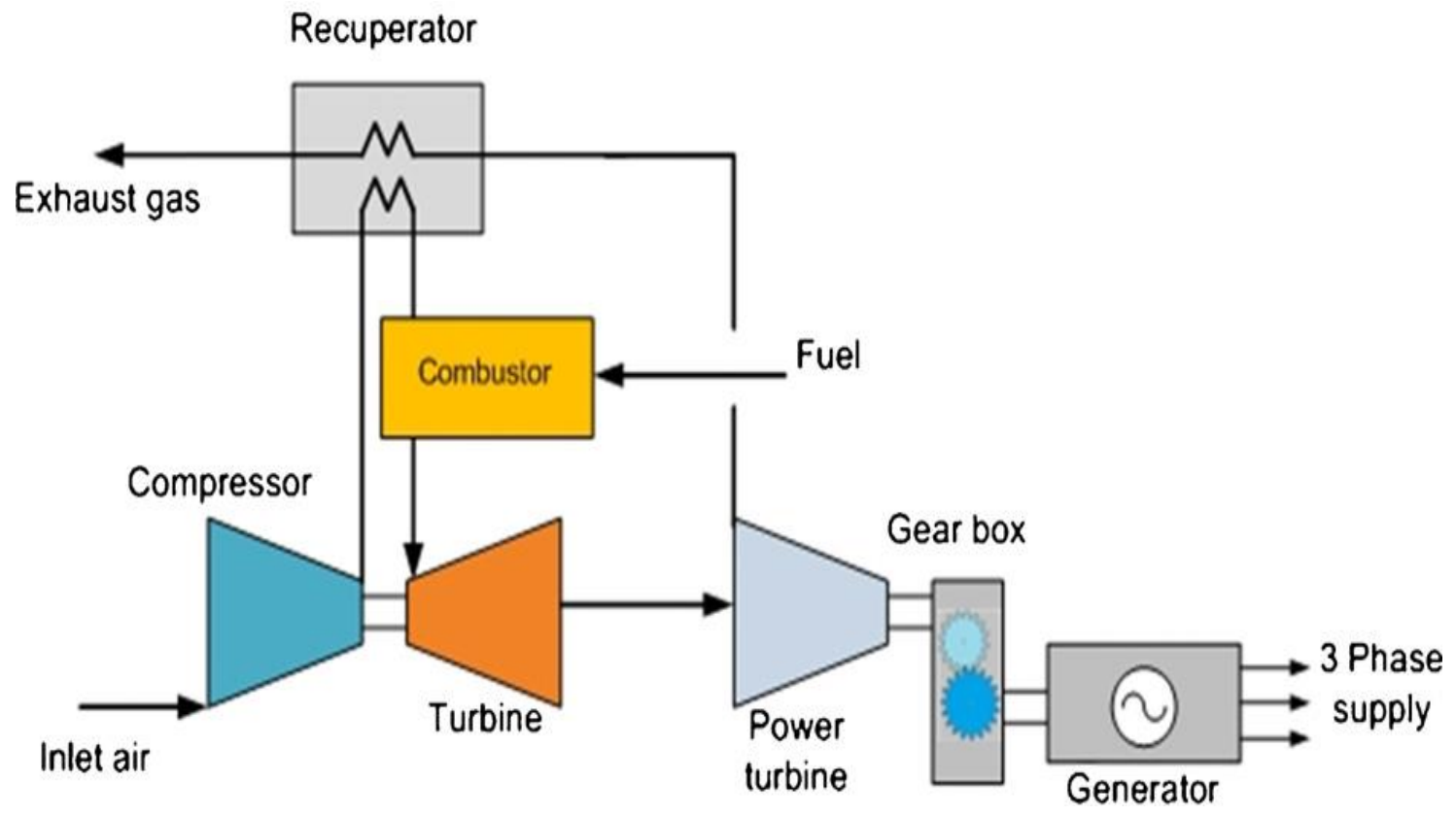

Figure1: Two-shaft MGT via a gearbox to generator

\section{MIMO MGT Model with PID controller:}

There are a large literature on the modelling of gas turbines, with varying level of complexity depending on the intended application. The concept of gas turbine system presented in this section is based on the paper presented by Rowen [3]. He proposed a single-shaft design, generator driven gas turbine model which includes speed control, temperature control and fuel system. This model was successfully adopted by the several authors for gas turbine simulations as well as for micro-turbine simulations with smaller time constants [4]. The three control functions of the micro-turbine are: speed control acting under part load conditions, temperature control acting as an upper output power limit, and acceleration control to prevent over speeding. The output of these control function blocks with $\left(\mathrm{P}_{\mathrm{e}}\right)$ mechanical power control are all inserted to a least value gate (LVG), whose output is the lowest of the four inputs and results in the least amount of fuel to the compressor-turbine as shown in figure (2). This figure shows the per-unit presentation of a micro-turbine, along with its control systems [4]. Each subsystem of the micro-turbine is discussed in the following subsections. 


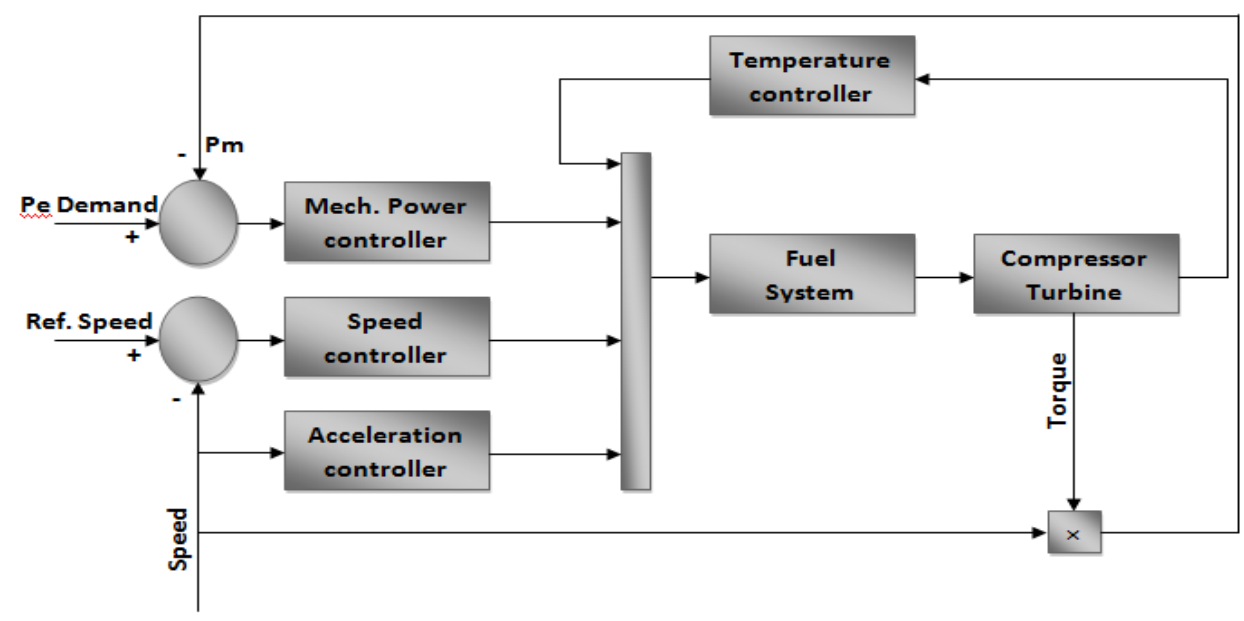

Figure 2: Micro-turbine system and its controllers

\section{Speed and acceleration loop controllers.}

The speed control operates on the speed error formed between a reference (one per-unit) speed and the MTG system rotor speed. It is the primary means of control for the microturbine under part load conditions. Speed control is usually modelled by using a lead-lag transfer function, or by a PID controller [4]. A PID controller has been used to present the speed controller, as shown in figure (3). In this figure the PID controller which has been used is maintained by changing the P,I and D parameters of the controller to reach the acceptable response on output using trial and error method as will discuss later. Acceleration control is used primarily during turbine start-up to limit the rate of the rotor acceleration prior to reaching operating speed. If the operating speed of the system is close to its rated speed, the acceleration control could be eliminated in the modelling, which is the case in this study.

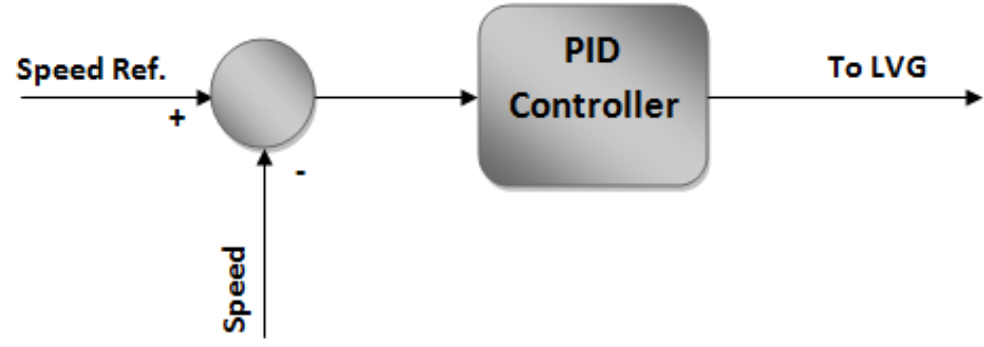

Figure3: PID speed controller 
Micro gas turbine simulation and control

\section{$4 \quad$ Fuel system.}

The fuel system consists of the fuel valve and actuator. The fuel flow comes out from the fuel system results from the inertia of the fuel system actuator and the valve positioner [3] The valve positioner transfer function is:

$\mathrm{E}_{1}$

$=\frac{\mathrm{K}_{\mathrm{vv}}}{\mathrm{T}_{\mathrm{v}} \mathrm{s}+\mathrm{c}} \mathrm{F}_{\mathrm{d}}$

and the fuel system actuator transfer function is:

$\mathrm{W}_{\mathrm{f}}$

$=\frac{\mathrm{K}_{\mathrm{f}}}{\mathrm{T}_{\mathrm{f}} \mathrm{S}+\mathrm{c}} \mathrm{E}_{1}$

In equation (1) and (2), $\mathrm{K}_{\mathrm{vv}}$ and $\left(\mathrm{K}_{\mathrm{f}}\right)$ is the valve positioner (fuel system actuator) gain, $\mathrm{T}_{\mathrm{v}}$ , $\mathrm{T}_{\mathrm{f}}$ are the valve positioner and fuel system actuator time constants, $\mathrm{c}$ is a constant, $\mathrm{F}_{\mathrm{d}}$ and $\mathrm{E}_{1}$ are the input and outputs of the valve positioner and $W_{\mathrm{f}}$ is the fuel demand signal in p.u. The output of the LVG, $V_{\text {ce }}$, represents the least amount of fuel needed for that particular operating point and is an input to the fuel system. Another input to the fuel system is the perunit turbine speed $\mathrm{N}$ (limited by the acceleration control). The per-unit value for $\mathrm{V}_{\text {ce }}$ corresponds directly to the per-unit value of the mechanical power on turbine at steady-state. The fuelflow control as a function of $\mathrm{V}_{\mathrm{ce}}$ is shown below in figure (4).

The value of $V_{\text {ce }}$ is scaled by the gain $K_{3}\left(K_{3}=\left(1-K_{6}\right)\right)$, then delayed and offset by the minimum amount of fuel flow $K_{6}$ to ensure continuous combustion process in the combustion chamber. $\mathrm{K}_{6}$ is essentially the minimum amount of fuel flow at no-load, rated speed [4].

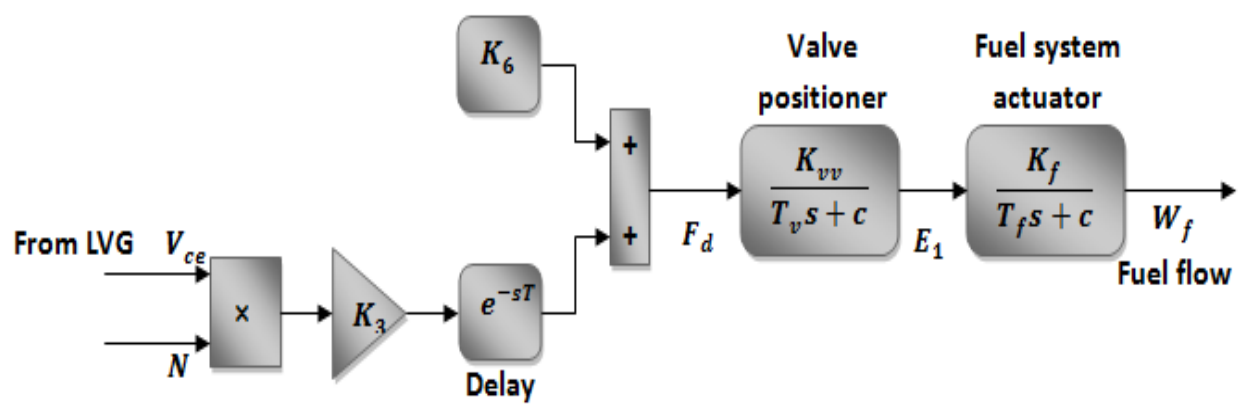

Figure4: Block diagram of the fuel system

\section{Compressor-Turbine system.}

The compressor-turbine is the heart of the micro-turbine and is essentially a linear, nondynamic device (with the exception of the rotor time constant) [4]. There is a small transport 
delay $\mathrm{T}_{\mathrm{CR}}$, associated with the combustion reaction time, a time lag $\mathrm{T}_{\mathrm{CD}}$, associated with the compressor discharge volume and a transport delay $\mathrm{T}_{\mathrm{TD}}$, for transport of gas from the combustion system through the turbine. The block diagram of the compressor-turbine package is shown in figure (5). In this figure both the torque and the exhaust temperature characteristics of the gas turbine are essentially linear with respect to fuel flow and turbine speed and are given by the following equations [4]:

Torque

$=\mathrm{K}_{\mathrm{HHV}}\left(\mathrm{W}_{\mathrm{f}_{2}}-0.23\right)$

$+0.5(1$

$-\mathrm{N})(\mathrm{Nm})$

Ext. $\mathrm{T}_{\mathrm{x}}$

$=\mathrm{T}_{\mathrm{R}}-700\left(1-\mathrm{W}_{\mathrm{f}_{1}}\right)$

$+550(1$

$-\mathrm{N})\left({ }^{\circ} \mathrm{F}\right)$

where $\mathrm{K}_{\mathrm{HHV}}$ is a coefficient which depends on the enthalpy or higher heating value of the gas stream in the combustion chamber and $T_{R}$ is the reference temperature. The $K_{H H V}$ and the constant 0.23 in the torque expression cater for the typical power/fuel rate characteristic, which rises linearly from zero power at 23\% fuel rate to the rated output at $100 \%$ fuel rate. The input to this subsystem is the p.u. fuel demand signal $\mathrm{W}_{\mathrm{f}}$ and outputs are the p.u. turbine torque (N.M) which multiplied by the rotor speed to result the mechanical power and exhaust temperature $\left({ }^{\circ} \mathrm{F}\right)$. Both mechanical power and temperature signals are controlled and inserted again into the LVG.

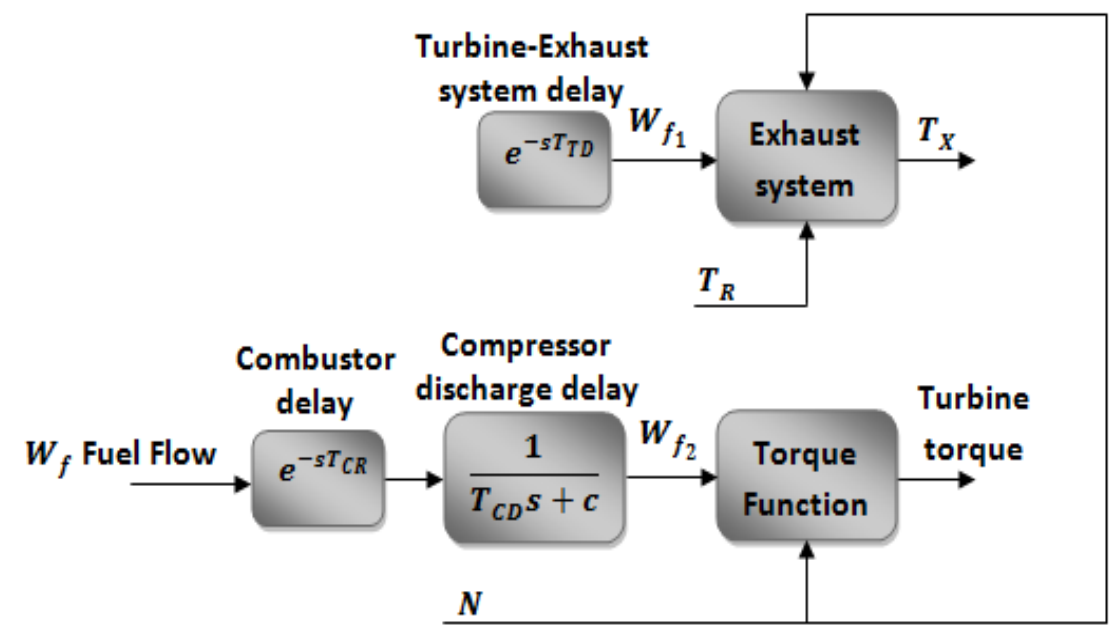

Figure5: Compressor-Turbine packge of MGT 
Micro gas turbine simulation and control

6 Temperature loop and PI controller.

Temperature control is the normal means of limiting the gas turbine output power at a predetermined firing temperature, independent of variation in ambient temperature or fuel characteristics. The fuel burned in the combustor results in turbine torque and in exhaust gas temperature. The exhaust temperature is measured using a series of thermocouples incorporating radiation shields as shown in the block diagram of the temperature controller Figure (6). In this figure, $T_{t}$ is the temperature controller integration rate and $T_{3}, T_{4}$ are time constants associated with the radiation shield and thermocouple, respectively. $\mathrm{K}_{4}$ and $\mathrm{K}_{5}$ are constants associated with radiation shield and $\mathrm{T}_{5}$ is the time constant associated with temperature controller. The output from the thermocouple is compared with a reference temperature, which is normally higher than the thermocouple output. This forces the output of the temperature control to stay on the maximum limit permitting the dominance of speed control through the LVG figure (3). When the thermocouple output exceeds the reference temperature, the difference becomes negative, and the temperature control output starts

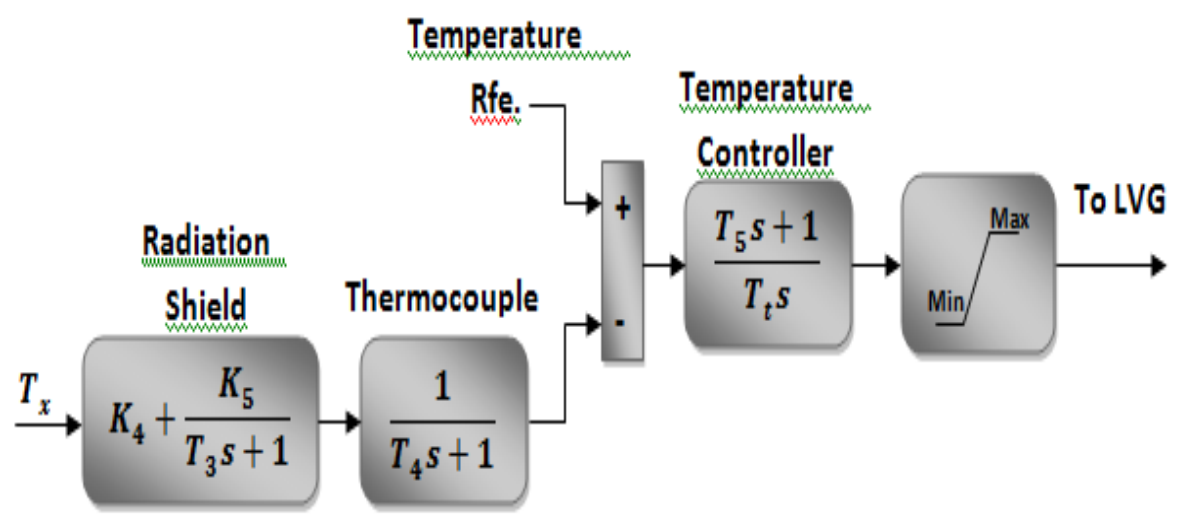

decreasing. When this signal Figure (3) becomes lower than the speed controller output, the former value will pass through the LVG to limit the turbine's output, and the turbine operates on temperature control. The input to the temperature controller is the exhaust temperature $T_{X}$ and the output is the temperature control signal to the LVG [4]

Figure6: Block diagram of temperature control system

\section{The generator.}

A conventional generator has been used in this study because of low speed generator to avoid the interface circuits (power electronic circuit) which used as have been said before in case of high speed generator, and also conventional generator is useful and suitable in countries where $50 \mathrm{~Hz}$ is mainly used. The electrical generator was modelled based on a generator swing differential equation. The swing differential equation is ascertained in terms of power [5]. 


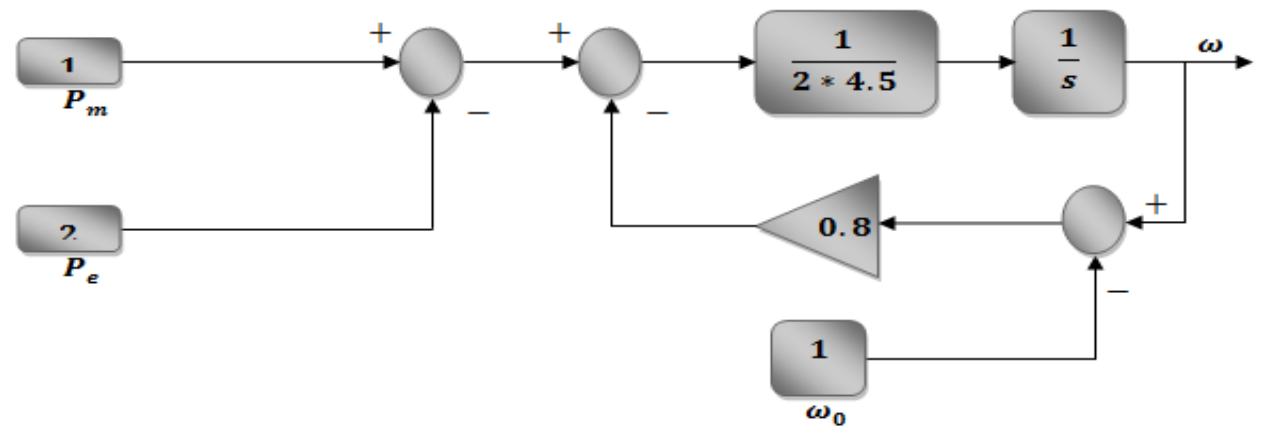

Figure7: Conventional generator

$$
\begin{aligned}
& \frac{\mathrm{d} \omega}{\mathrm{dt}} \\
& =\frac{\omega_{0}}{2 \mathrm{H}_{\mathrm{eq}}}\left[\mathrm{P}_{\mathrm{m}}-\mathrm{P}_{\mathrm{e}}\right. \\
& -\mathrm{D}_{\mathrm{eq}}(\omega \\
& \left.\left.-\omega_{0}\right)\right]
\end{aligned}
$$

Generator equation was modelled based on the assumption that losses, due to the shaft rotation are ignored [5]. The SIMULINK model representation of the electrical generator is shown in figure (7). The input as has been illustrated in figure (7) are the Mechanical power $\left(\mathrm{P}_{\mathrm{m}}\right)$ and Electrical power $\left(\mathrm{P}_{\mathrm{e}}\right)$ and the output was the rotor speed $\omega$ of the generator which has been inserted into the turbine as a feedback.

\section{MGT loops, PID tuning, and simulation tests.}

A step function has been applied as input of electrical power as set point (from zero to 0.2) p.u (Per Unit). The reference rotor speed was 1 p.u. in all simulation. The reference exhaust temperature also fixed at $950 \mathrm{oF}$. The output response results after parameters of PID maintained using trial \& error method and Ziegler-Nichols method were applied. The figure (8) shows the output response of electrical power demand $\left(\mathrm{P}_{\mathrm{e}}\right)$ and mechanical power $\left(\mathrm{P}_{\mathrm{m}}\right)$ outputs after applying the Ziegler-Nichols method on PID controller of $\mathrm{P}_{\mathrm{e}} \& \mathrm{P}_{\mathrm{m}}$. The parameters in figure (8) were as following: 


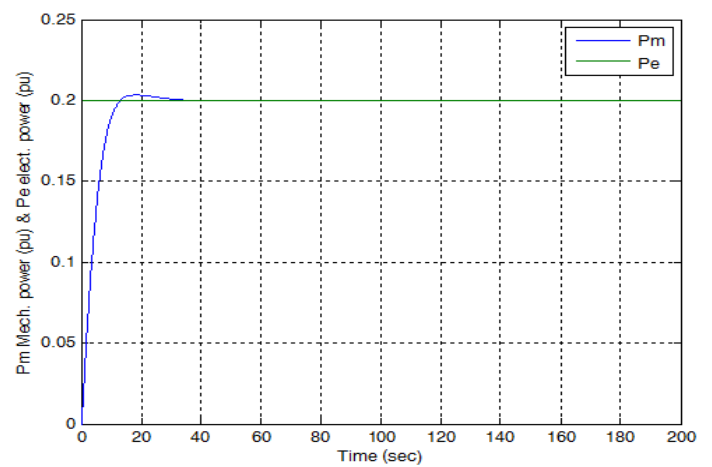

Figure8: Relationship between $\mathrm{P}_{\mathrm{e}} \& \mathrm{P}_{\mathrm{m}}$ with Ziegler-Nichols method $\mathrm{Tu}=0.5, \mathrm{Kc}=12, \mathrm{Kp}=0.2 * 12, \mathrm{Ki}=0.5 / 2=0.25$ and $\mathrm{Kd}=0.5 / 8=0.0625$

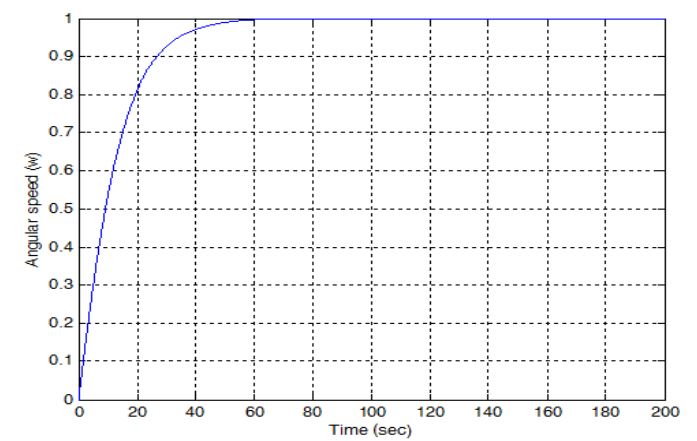

Figure9: Speed $(\omega)$ with Trial \& error method.

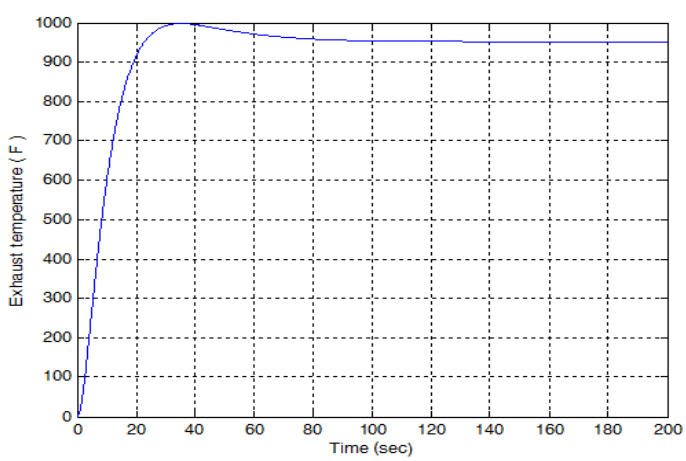

Figure10: Exhaust temperature $\left({ }^{\circ} \mathrm{F}\right)$

Ziegler-Nichols method was applied and found suitable parameter for mechanical power PID controller, whereas could not be applied with Angular speed PID controller and also in temperature PI controller. Trial \& error method is the perfect method for both angular speed PID controller and temperature PI controller. Figure (9) shows the response of Angular speed PID controllerusing Trial \& Error method. Angular speed $\omega(\mathrm{pu})$ PID controller using Trial \& error method. PID parameter of: $\mathrm{Kp}=1, \mathrm{Ki}=21$ and $\mathrm{Kd}=0.5 \mathrm{~N}=2$ 
Ibrahim et al., CEST-2018, AIJR Proceedings 2, pp.141-158, 2018

Exhaust temperature is illustrated in figure (10) with parameter of PI controller using Trial \& Error where : $\mathrm{P}=1$ and $\mathrm{I}=2$. Figure (11) illustrate the main structure of Micro-turbine using MATLAB/Simulink, power demand $\left(\mathrm{P}_{\mathrm{e}}\right)$, feedback of angular speed $(\omega)$, and $(\mathrm{TR})$ exhaust temperature set-point. All are represent the inputs of the Micro-turbine itself. The output of the Micro-turbine obviously are the mechanical power $\left(\mathrm{P}_{\mathrm{m}}\right)$, rotor speed $(\omega)$, and measured exhaust temperature.

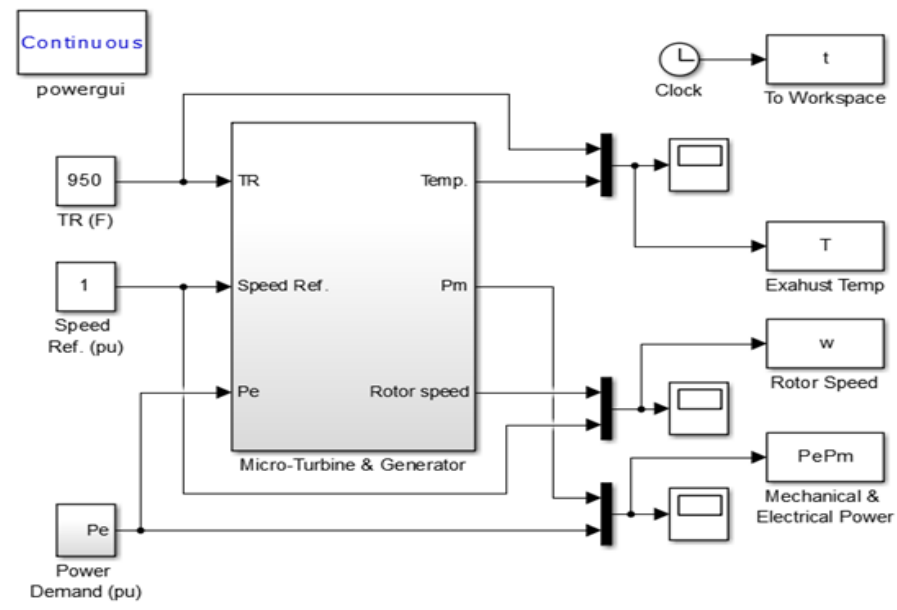

Figure11: Main structure of MGT on MATLAB/Simulink

\section{Identification and model reduction of MIMO MGT with PID controller.}

\subsection{Mechanical \& electrical power loop.}

Estimation and validation of the output signal could be represented for mechanical power PID controller, angular speed PID as well and also for PI controller exhaust temperature by do several calculations the transfer function of speed loop with PID controller was as follows.

$\mathrm{G}_{\mathrm{T} 1}$

$=\frac{0.08}{s^{2}+0.45 s+0.08}$

To validate the response of mechanical power PID controller, figure (12) shows the actual and estimated values of that. With the same step input of both and we could obviously compare the two values to each other. The blue curve for $\left(\mathrm{P}_{\mathrm{m}}\right)$ actual value and the red curve for $\left(\mathrm{P}_{\mathrm{m}}\right)$ estimated value were approximately the same: 


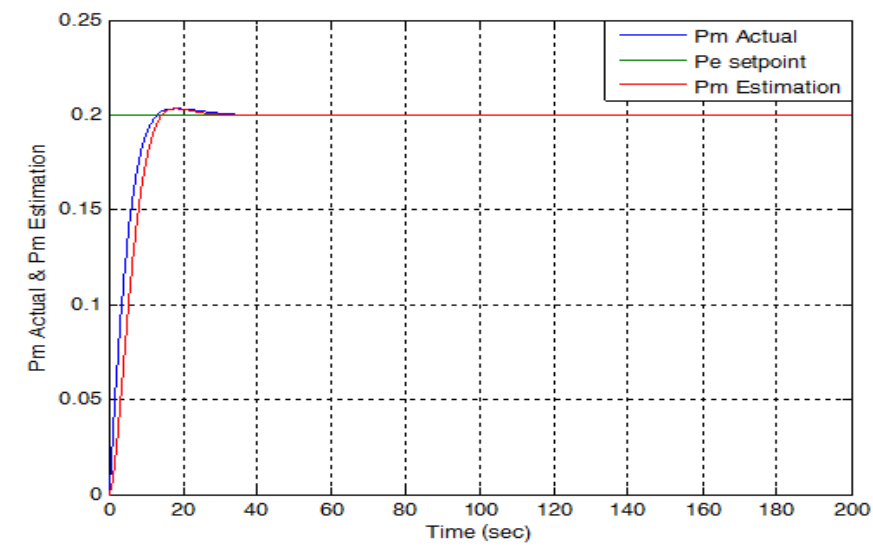

Figure12: Actual and estimation values of mech. power response.

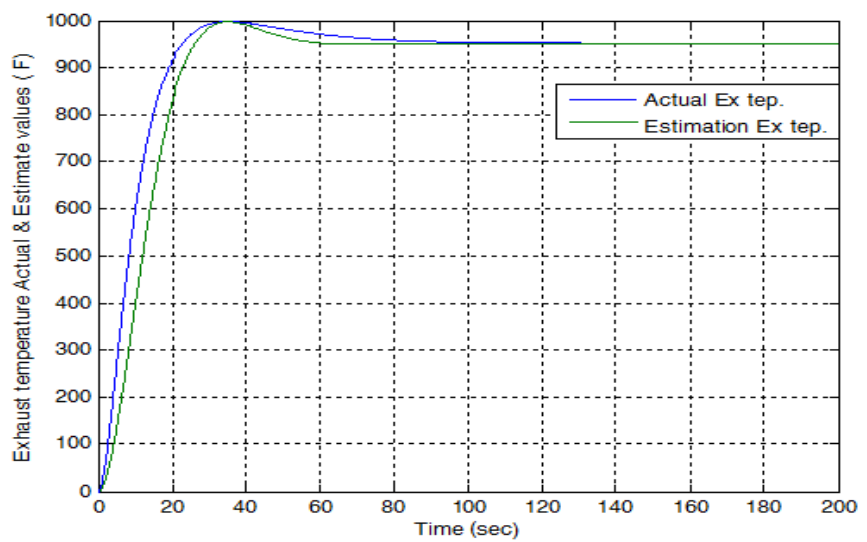

Figure13: Actual and estimation values of Exh.Tem. $\left({ }^{\circ} \mathrm{F}\right)$ response.

\subsection{Exhaust temperature loop.}

In the same way exhaust temperature has been estimated and validated $\mathrm{y}_{\max }=995.3$, $\mathrm{y}_{\mathrm{ss}}=950 \mathrm{t}_{\mathrm{p}}=35 \mathrm{sec}$. After several calculations has been done as above a results found were $: \zeta=0.696 \omega_{\mathrm{n}}{ }^{2}=0.0156$. The transfer function of $\mathrm{G}_{\mathrm{T} 2}$ will be as follows:

$\mathrm{G}_{\mathrm{T} 2}$

$=\frac{0.0156}{\mathrm{~s}^{2}+0.174 \mathrm{~s}+0.0156}$

Figure (13) illustrate the actual (blue curve) and estimation values (green curve) of Exhaust temperature. As we can see the output response of the actual and the estimation value are approximately the same. 


\subsection{Rotor speed loop.}

By getting values of $\mathrm{y}=0.6318, \mathrm{y}_{\mathrm{ss}}=1 \tau=12.56 \mathrm{sec} \quad$ from the rotor speed PID controller and substituting these values in the following first order transfer function equation which represent the rotor speed as follows:

$\mathrm{G}_{\mathrm{T} 3}=\frac{1}{12.56 \mathrm{~s}+1}$

The figure (14) shows the actual and estimated values of rotor speed $(\omega)$ pu output response and as we could see are the same.

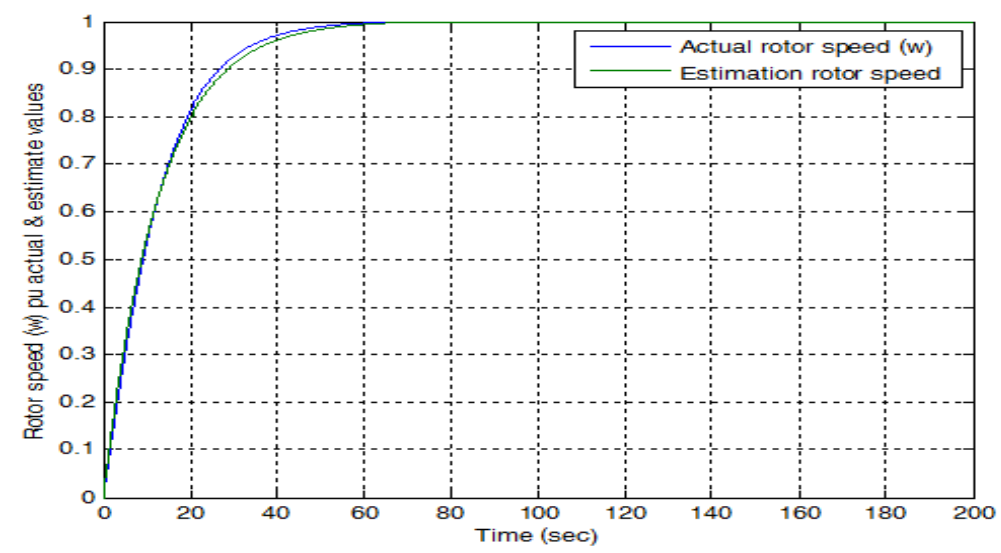

Figure14: Actual \& estimated values ofrotor $\operatorname{speed}(\omega)$ output response

\section{Compensators design instead of PID and PI controllers.}

The design of feedback control system in industry is probably accomplished using frequencydomain more often than other method. The primary reason for the popularity of frequencydomain design is that the effects of disturbances, sensor noise, and plant uncertainties are relatively easy to visualize and assess in the frequency domain [6]. In this section PID controller in power and speed controller, also temperature PI controller will be replaced with lag compensator.

\subsection{Lag Compensation For MGT Speed Controller}

Mathematical model of speed controller PID for the micro-turbine which we have been discussed in chapter four, as follows :

$P+I\left(\frac{1}{s}\right)$

$+\mathrm{D}\left(\frac{\mathrm{N}}{1+\mathrm{N}\left(\frac{1}{\mathrm{~s}}\right)}\right)$

By getting the values of $\mathrm{P}, \mathrm{I}, \mathrm{D}$, and $\mathrm{N}$ from MATLAB/Simulink speed PID controller shown in figure (10) the equation (14) will be as follow:

Proceedings of First Conference for Engineering Sciences and Technology (CEST-2018), vol. 1 
Micro gas turbine simulation and control

$\mathrm{PID}_{\text {(speed) }}=1+2\left(\frac{1}{\mathrm{~s}}\right)+\frac{1}{2}\left(\frac{2}{1+\frac{2}{\mathrm{~s}}}\right)$

By rearrange the equation to show the crossover frequencies of speed PID controller:

PID (speed)

$=\frac{4\left(\frac{1}{4} s+1\right)(s+1)}{s\left(\frac{1}{2} s+1\right)}$

To replace PID (speed) by a appropriate compensator we must use Bode plot of speed PID controller which could be seen in the figure (15):

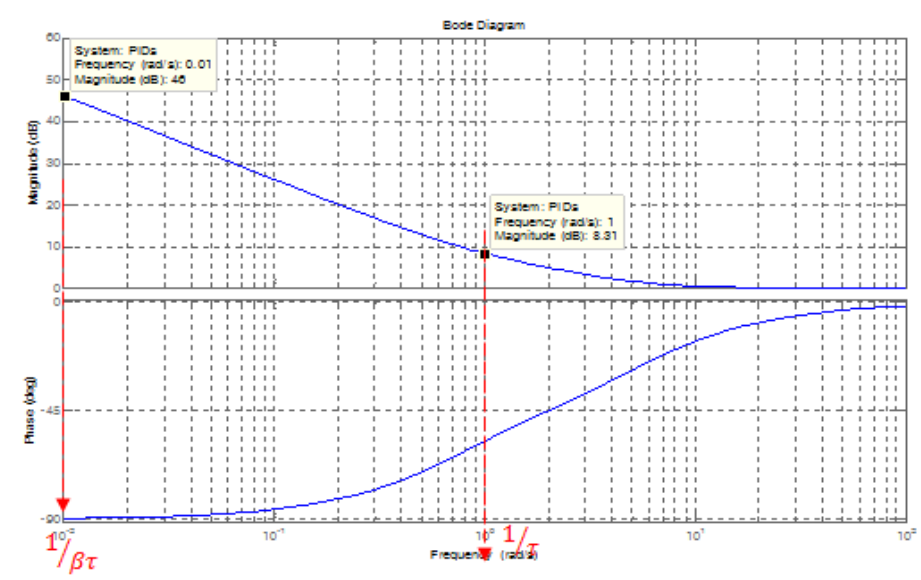

Figure15: Bode plot speed PID controller.

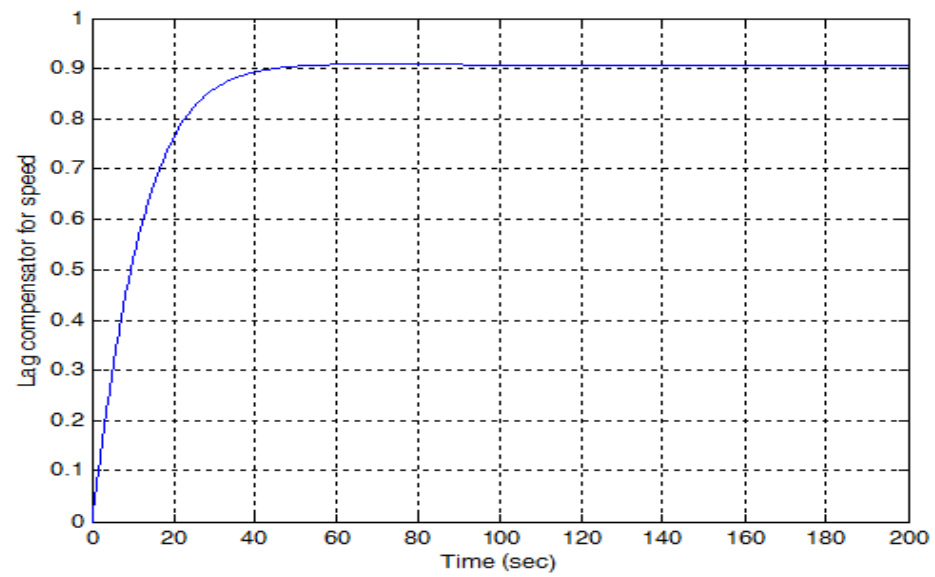

Figure16: Lag compensator response for speed loop.

As we could see the PID (speed) shape looks like a lag compensator with upper and lower gain crossover frequencies $(1 / \beta \tau)$ and $(1 / \tau)$ respectively: 
$D(s)=\frac{\tau s+1}{\beta \tau s+1}$

$=\frac{s+1}{100 s+1}$

as we could see the speed lag compensator response shown in figure (16) corresponding to equation (15) is acceptable except the gain which need to be increased. After increasing the lag compensator gain, equation (15) will be as follows and speed lag compensator response is then shown in figure (17). Bode plot of both PID speed controller and Lag compensator shown in figure (17) illustrate that the gain crossover frequency are nearly the same (lower is $0.01 \mathrm{rad} / \mathrm{sec}$ and the upper is $0.1 \mathrm{rad} / \mathrm{sec}$ ).

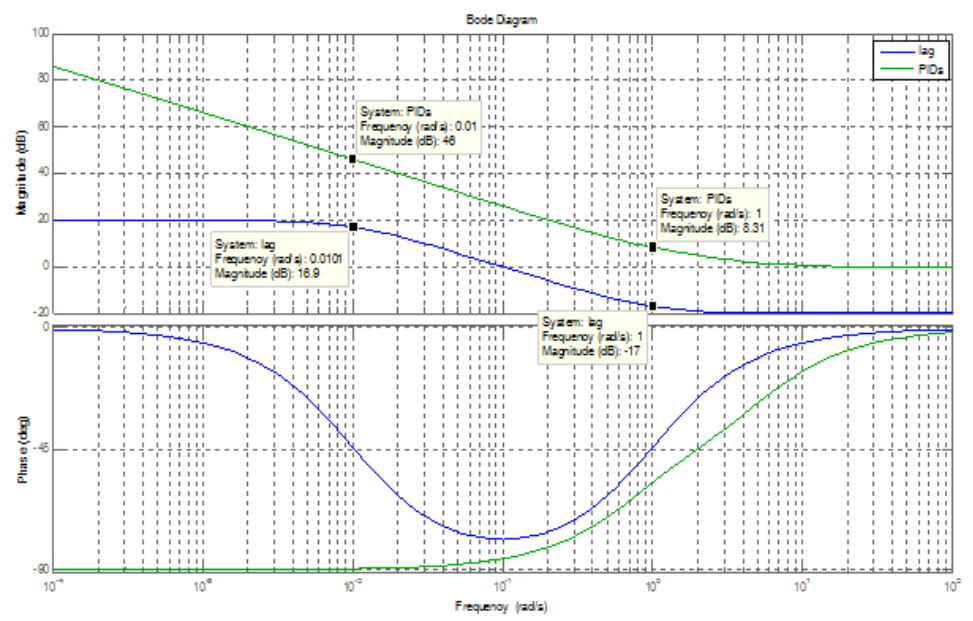

Figure17: Bode plot of lag compensator and PID for speed.

$\mathrm{D}(\mathrm{s})$

$=\frac{10 s+10}{100 s+1}$

\subsection{Lag Compensation For MGT Mechanical Power:}

As we have been done in PID speed controller a lag compensator for mechanical power is shown in figure (18)

$\mathrm{D}(\mathrm{s})=\frac{\tau \mathrm{s}+1}{\beta \tau \mathrm{s}+1}$

$=\frac{10 \mathrm{~s}+1}{100 \mathrm{~s}+1}$

As we could see the mechanical power lag compensator response shown in figure (18) corresponding to equation (17) is acceptable except the gain which need to be increased.After increasing the lag compensator gain, equation (17) will be as follows and mechanical power lag compensator response is then shown in figure (19):

Proceedings of First Conference for Engineering Sciences and Technology (CEST-2018), vol. 1 
Micro gas turbine simulation and control

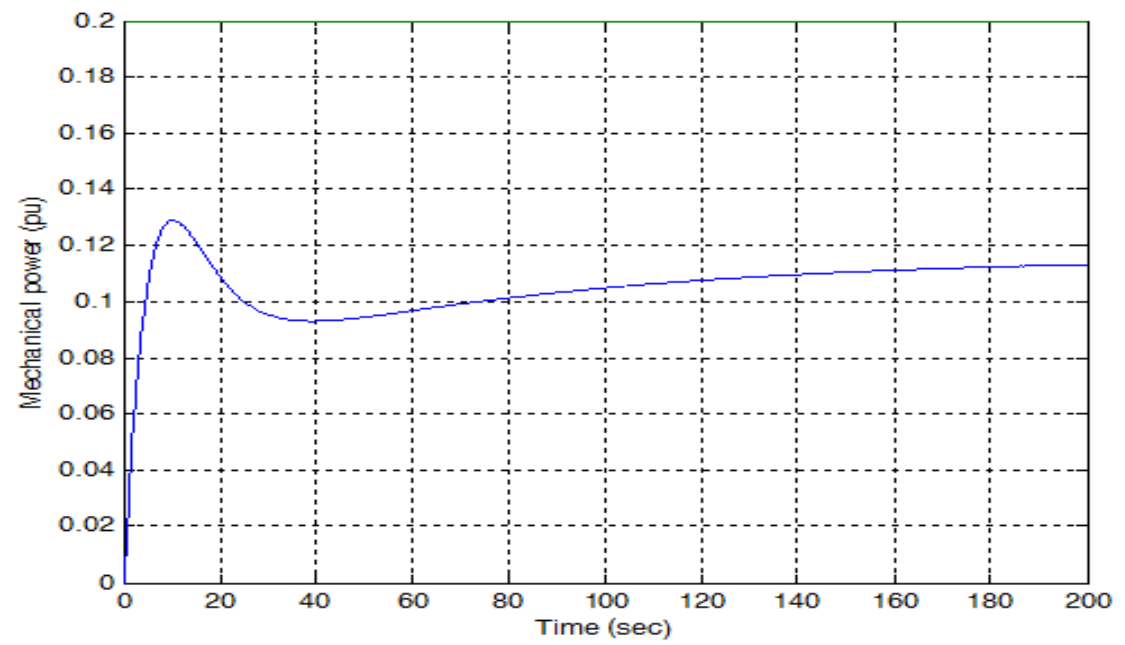

Figure18:Lag compensator response for Mech. power

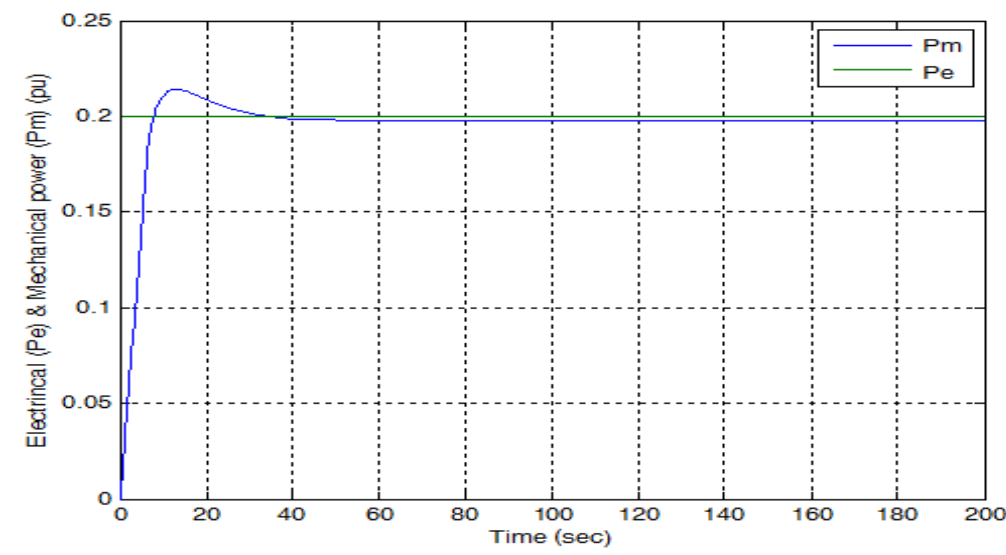

Figure19:Lag compensator response for mech. power after maintaining

$\mathrm{D}(\mathrm{s})$

$=\frac{600 s+60}{100 s+1}$

Figure (20) shows the comparison between Bode plot of the both mechanical power PID and mechanical power lag compensator which we have been gotten according to eq. (18). Bode plot of both PID mechanical power controller and Lag compensator shown in figure (20) illustrate that the gain crossover frequency are nearly the same (lower is $0.001 \mathrm{rad} / \mathrm{sec}$ and the upper is $0.1 \mathrm{rad} / \mathrm{sec}$ ). 


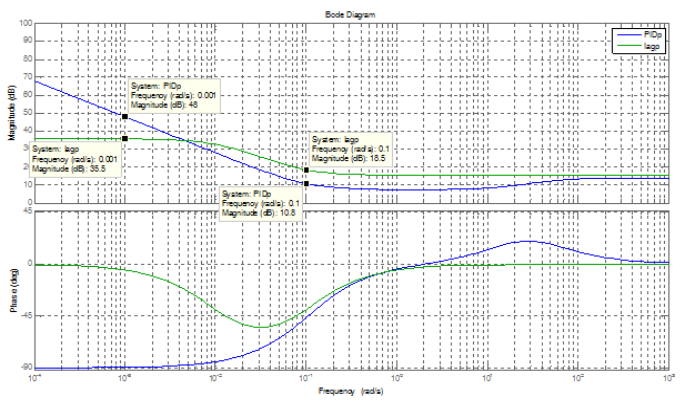

Figure20:Lag compensator response for Mech. power

\subsection{Lag compensation for MGT temperature controller:}

The mathematical model of Exhaust temperature PI controller for the micro-turbine which we have been discussed in section 9, as follows :

$\mathrm{P}$

$+\mathrm{I}\left(\frac{1}{\mathrm{~s}}\right)$

By getting the values of (P) and (I) from MATLAB/Simulink Exhaust temperature PI controller shown in figure (11) the equation (19) will be as follow:

$$
P I_{(\mathrm{Tem})}=1+2\left(\frac{1}{\mathrm{~s}}\right)
$$

After getting the upper and lower gain cross over frequencies of the PI exhaust temperature controller bode plot, it was replaced with a lag compensator as in equation (20) and its resonse is shown in figure (21)

$$
\begin{aligned}
& D(s)=\frac{0.5 s+1}{s+1} \\
& =\frac{s+2}{10 s+1}
\end{aligned}
$$

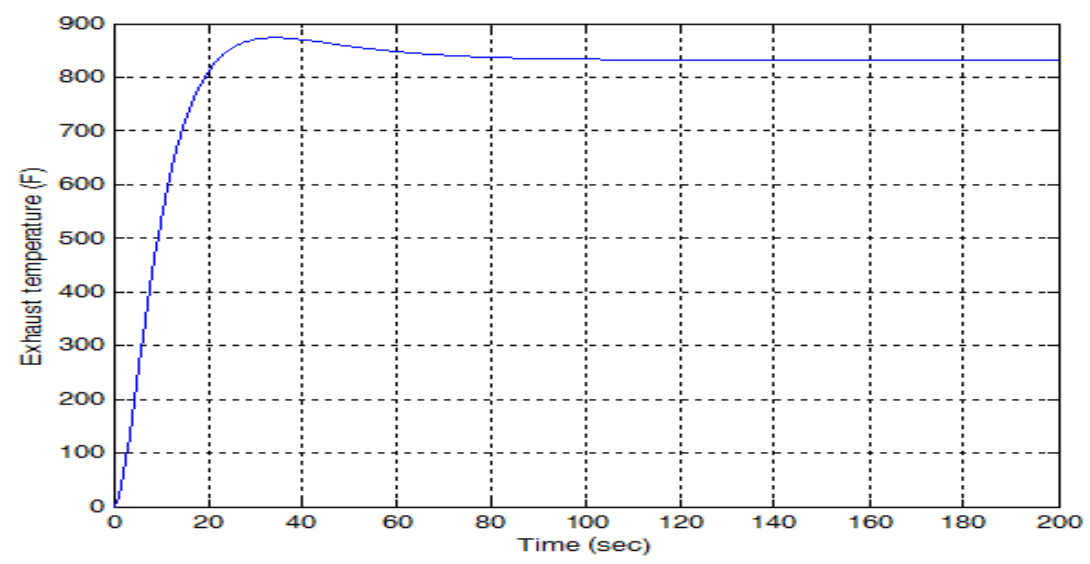

Figure21:Exh. temperature lag compensator response

Proceedings of First Conference for Engineering Sciences and Technology (CEST-2018), vol. 1 
Micro gas turbine simulation and control

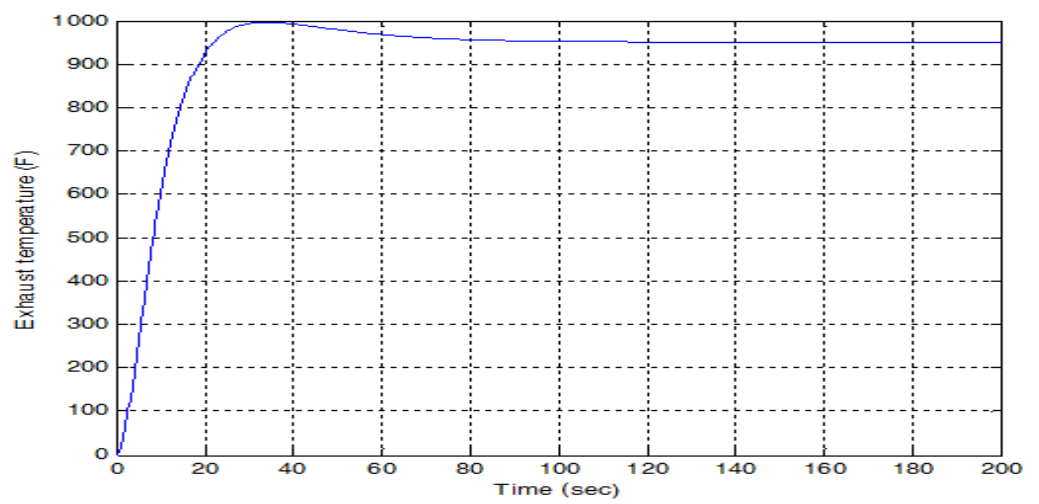

Figure22:Exh.temperaturelag compensator response after maintaining

According to fact which has (usually, as a general guideline, the upper corner frequency, $1 / \tau$, of the compensator should be approximately one octave to one decade below the new gain crossover frequency $\omega_{\mathrm{g}}^{\prime}$.) Taking:

$$
\frac{1}{\tau}=\frac{\omega_{g}^{\prime}}{10}=\frac{2}{10} \rightarrow \tau=5
$$

thus, the required lag compensator is:

$\mathrm{D}(\mathrm{s})$

$=\frac{5 s+1}{100 s+1}$

equation(20) will be as follows and Exhaust temperature lag compensator response is then shown in figure (22).

Bode plot of both PI Exhaust temperature controller and Lag compensator shown in figure (23) illustrate that both plots are nearly the same, Notice that the sample Exh. = Exhaust and Tem. $=$ Temperature.

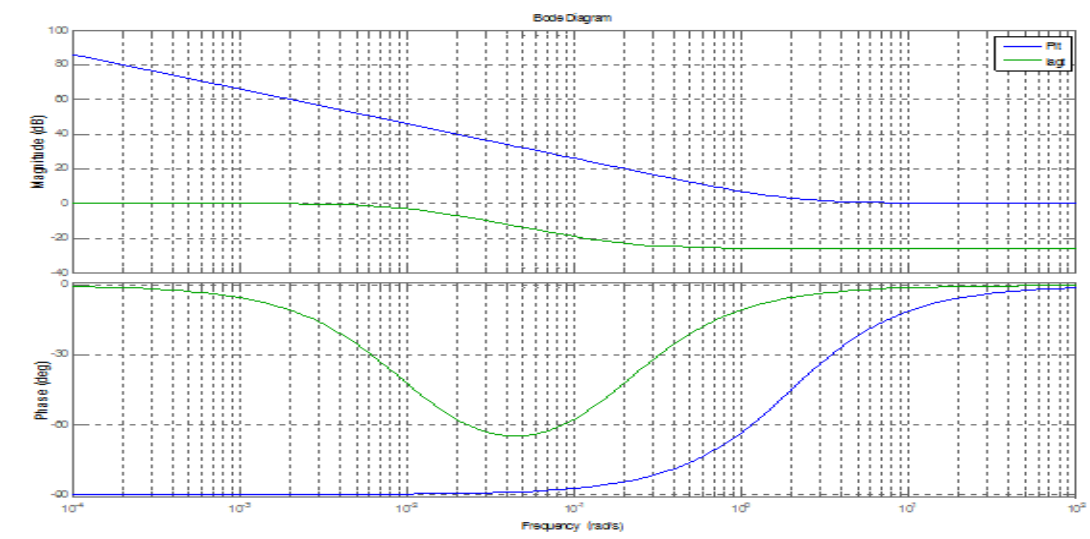

Figure23: Bode plot of lag compensator and PI for Exh.Tem. 

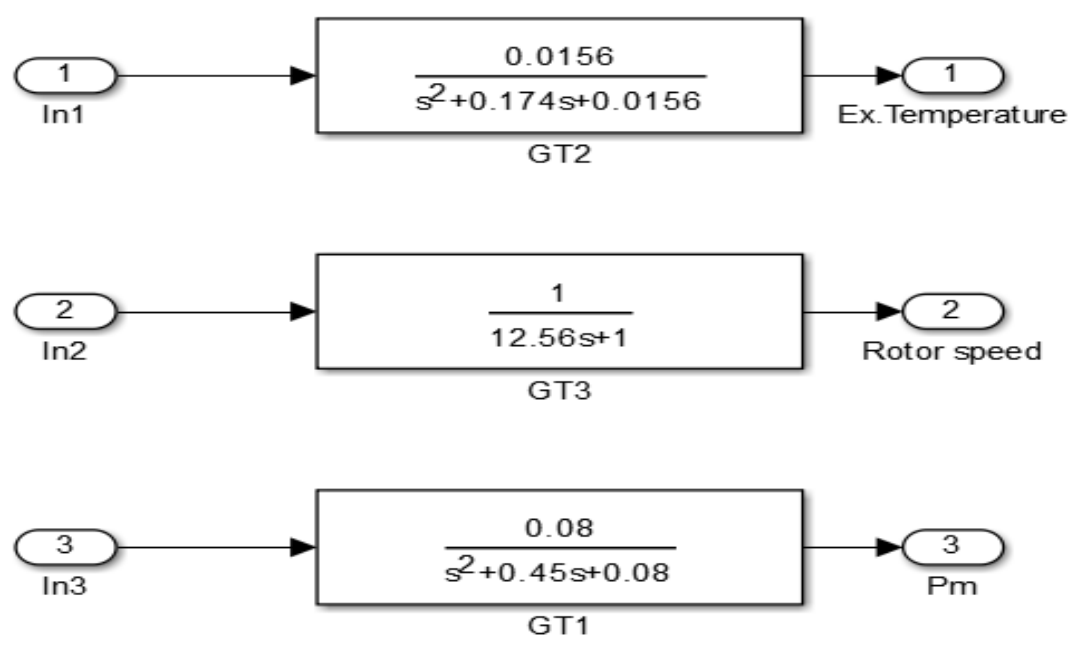

Figure24:Transfer function of power, speed and temp. systems

We could notice here that there is no interaction between the three controllers, which supervisor controller is allowable to design. The whole system is stable and could be used in industrial. Figure (24) shows the collection of three PID controllers -exhaust temperature, mechanical \& electrical power and rotor speed- to build what is known of supervisor controller. The whole systems and supervisor controller itself all are shown in figure (25).

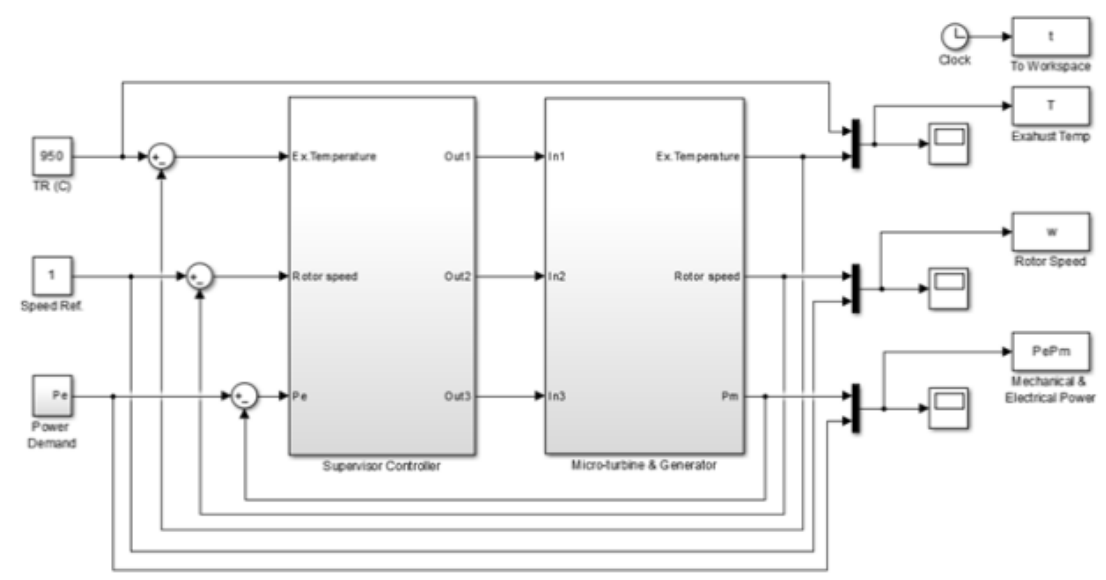

Figure25: The plant of Micro-Turbine and generator.

\section{Conclusion:}

The main purpose of this paper is to model, simulate, and control design of the Micro-turbine which mainly used to maintain the continuously of electrical power of the grid. The simulation

Proceedings of First Conference for Engineering Sciences and Technology (CEST-2018), vol. 1 
Micro gas turbine simulation and control

model is used to investigate the output response as well. Local controller was designed for Micro-turbine using PID controllers for both rotor speed and mechanical \& electrical power systems, and a PI controller for exhaust temperature. The PID, and PI controllers tuned using Ziegler-Nichols method for Mechanical \& electrical power PID controller and have been found suitable whereas, using trial \& error was better for rotor speed and exhaust temperature systems, to reach an acceptable and particular output of the Micro-turbine systems. A compensators were designed for three systems -rotor speed, mechanical \& electrical power, and exhaust temperature systems- instead of PID and PI controllers which have been designed before, using frequency domain with help of Bode plot reshaping. Interaction hasn't been detected between three systems. System reduction was resulted due to a MIMO (Multi-Input Multi-Output) system becomes a SISO (Single-Input Single -Output) system. Estimation and validation were both done for the PID and PI controllers. A supervisor control system was designed by collected the three IMC-based controllers and applied to the Micro-turbine. The time constant parameters were chosen to get the acceptable output responses.

\section{References:}

[1] P.RajaSekhar, L.S Enhancement of Micro Turbine-Generator Output Voltage Quality through Application of Matrix Converter Interface uresh, ', IOSR Journal of Engineering (IOSRJEN) PP 43-49 , (2013).

[2] Larry Goldstein, Bruce Hedman, Dave Knowles, Steven I. Freedman, Richard Woods and Tom Schweizer., "Gasfired distributed energy resource technology characterizations," National Renewable Energy Laboratory, NREL/TP620-34783, Nov.(2003).

[3] W. I. Rowen, 'Simplified mathematical representations of heavy duty gas turbines',, Journal of Engineering for Power, Trans. ASME, vol. 105, no. 4,pp. 865-869, October (1983).

[4] GodswillOfualagba, 'The Modelling and Simulation of a Micro-turbine Generation System', IJSER International Journal of Scientific \& Engineering Research Volume 2, Issue 2, ISSN 2229-5518, (2012).

[5] Emekaeusebiusomeife, 'The impact of compressor cleaning in gas turbine engines used for oil and gas applications', Msc. in communication, control and digital signal processing, (2010).

[6] M. Gopal, 'Control system principle and design', McGraw-Hill companies, (2008). 